\title{
USING SPACE SYNTAX TO DETERMINE THE FORM AND PATTERN OF HERITAGE SITE (Case Study: Sangiran Heritage Site)
}

\author{
Mila Karmilah ${ }^{1)}$ \\ Nyandra Sari Magfiroh ${ }^{2}$ \\ Prodi Perencaan Wilayah dan Kota Universitas Islam Sultan Agung ${ }^{1,2}$ \\ Penulis Korespondensi e-mail : mila.k@unissula.ac.id
}

\begin{abstract}
There are 10 criteria of world heritage sites that have been set by UNESSCO. The category is divided into two categories of cultural sites and natural sites. Area of Ancient Human Site in Sangiran is included in the category of cultural sites. Sangiran region has begun to develop since 2005. In 2012 the government to plan and develop on a large scale so that now the region currently has 5 museums with international standard. From this activity began to appear very significant changes to the region Sangiran. The growth of trade, settlements, tourism and service has influenced regional shape and form.

To know the changes that occur in the region of Sangiran the studied used space syntax analysis method, which in its approach using a quantitative approach. The space syntax analysis method will be adjusted with the steps of configuration method. The analysis variables used are the characteristics of the region, the anatomy of the region and the blueprint of the expanse. Using various indicators such as scarcity, historicity and scientific value, and the road net. In conformity with the variables and indexes that have been brought up, is expected to produce research output in accordance with the title, the Form and Pattern of Ancient Site Site Sangiran, Sragen regency. The result of this study shows that Sangiran area tends to be fragmented cities, with space syntax R2 value of 0.012714 (intelligibility value). In addition, based on the pattern of development of the Sangiran region in the form of dispersing pattern. This is due to the development of homogeneous economic activities and parallel to the road network.

Keywords : space syntax, determine, form and pattern, heritage site
\end{abstract}

\begin{abstract}
ABSTRAK
Terdapat 10 kriteria situs warisan dunia yang telah di tetapkan oleh UNESSCO dan dikatagorikan menjadi dua bagian yaitu katagori situs budaya dan situs alam. Kawasan Situs Manusia Purba yang ada di Sangiran ini termasuk dalam katagori situs budaya. Kawasan Sangiran mulai berkembang pada tahun 2005 kawasan ini hanya berdiri satu bangunan berbentuk joglo sehingga tidak berdampak besar di sekitar kawasan. Pada 2012 pemerintah melakukan perencanaan dan pembangunan secara besar-besaran sehingga sekarang kawasan heritage ini telah memiliki 5 museum berstandar internasional. Dari kegiatan tersebut terjadi perubahan yang sangat signifikan terhadap kawasan pariwisata, permukiman, perdagangan dan jasa yang berpengaruh terhadap bentuk dan pola kawasan.

Untuk mengetahui adanya perubahan di kawasan Sangiran, digunakan pendekatan kualitatif dengan metode space syntax. Metode ini akan menggunakan analisis space syntax dan disesuaikan dengan langkah-langkah metode konfigurasi. Variabel analisis yang digunakan adalah karakteristik wilayah, anatomi wilayah dan cetak biru hamparan. Menggunakan berbagai indikator seperti kelangkaan, historisitas dan nilai ilmiah, dan jaring jalan. Sesuai dengan variabel dan indeks yang telah dikemukakan, diharapkan dapat menghasilkan output penelitian sesuai dengan judul, Bentuk dan Pola Situs Situs Kuno Sangiran, Kabupaten Sragen. Hasil dari penelitian ini menunjukkan bahwa daerah Sangiran cenderung menjadi kota yang terfragmentasi, dengan nilai R2 sintaksis ruang 0,012714 (nilai kejelasan). Selain itu, berdasarkan pola perkembangan wilayah Sangiran dalam bentuk pola pendispersi. Hal ini disebabkan perkembangan kegiatan ekonomi yang homogen dan sejajar dengan jaringan jalan.

Keywords : space syntax, determine, form and pattern, heritage site
\end{abstract}


Jurnal Planologi Vol. 15, No. 1, April 2018

Available : http://jurnal.unissula.ac.id/index.php/psa

\section{PENDAHULUAN}

Pelestarian cagar budaya merupakan salah satu jenis pendekatan dalam perencanaan kota atau penataan ruang yang bertujuan untuk mempertahankan, melindungi, memelihara serta memanfaatkan bangunan cagar budaya demi kepentingan pembangunan (Krisnawati, Lilik dan Rima, Suprihardjo Dewi, 2014). Kawasan Cagar Budaya merupakan salah satu kawasan yang menjadi prioritas pengembangan oleh pemerintah. Keberadaan kawasan ini merupakan potensi khusus bagi sebuah daerah dan akan menjadi ciri khas dari sebuah daerah. Perkembangan kawasan ini menjadi salah satu dampak yang luar biasa terhadap kawasan karena dapat merubah bentuk tata guna lahan. Dengan adanya kegiatan pengembangan ini sering menjadikan bentuk dan pola kawasan cukup bervariatif sehingga mengakibatkan bervariasinya kegiatan yang ada di sekitarnya.

Menurut UNESCO, pengertian heritage adalah warisan (budaya) masa lalu, apa yang saat ini dijalani manusia, dan apa yang diteruskan kepada generasi yang akan datang. Sedangkan menurut kamus bahasa inggris indonesia yang di susun oleh John M Echols dan Hassan Shadily makna heritage adalah sebuah warisan dan pusaka. Dan dalam kamus Oxford, makna heritage adalah sebagi sejarah, tradisi dan nilai yang dimiliki suatu bangsa atau negara yang selama bertahun-tahun dan dianggap sebagai bagian penting dari karakter bangsa atau negara yang dimaksud. Dari berbagai pengertian yang telah disampaikan di atas dapat ditarik kesimpulan bahwa heritage merupakan warisan budaya manusia yang harus dilestarikan sehingga manusia sekarang dan yang akan datang dapat mengetahui sejarang tentang bangsa dan negaranya.

Setiap heritage memiliki sejarahnya masing-masing. Heritage tidak selalu berupa benda mati, namun dapat berupa makhluk hidup ataupun yang sejenis. Heritage dapat digunakan sebagai icon suatu daerah tertentu yang melambangkan peristiwa besar ataupun peninggalan yang ada pada suatu daerah tersebut. Heritage merupakan bukti/ tanda petunjuk aktivitas yang dimiliki dan masih terus mempunyai nilai sejarah yang penting. Heritage merupakan bagian dari nilai sosial catatan kehidupan keseharian masyarakat. Disamping itu, nilai-nilai yang dimiliki heritage juga merupakan catatan yang mengisi kenangan dan adatistiadat masyarakat.

Menurut Synder dan Catanese dalam Budiharjo (1997), terdapat enam ciri-ciri heritage, yaitu: (1) kelangkaan, karya merupakan sesuatu yang langka atau dalam kamus bahasa Indonesia langka memiliki artisesuatu yang sulit di dapat dan sesuatu yang jarang ditemukan; (2) kesejarahan, yaitu memuat lokasi peristiwa bersejarah yang penting; (3) 
Jurnal Planologi Vol. 15, No. 1, April 2018

estetika, yaitu mempunyai keindahan bentuk struktur atau ornament; (4) superlativitas, yaitu tertua, tertinggi, atau terpanjang; (5) kejamakan, yaitu karya yang mewakili suatu jenis atau ragam bangunan tertentu; dan (6) pengaruh, yaitu keberadaanya akan meningkatkan citra lingkungan sekitarnya. Sedang Kerr (1983) menyebutkan bahwa terdapat 3 (tiga) ciri heritage yaitu : (1) Nilai Sosial, yaitu mempunyai makna bagi masyarakat; (2) Nilai Komersial, yaitu berpeluang untuk dimanfaatkan sebagaikegiatan ekonomis; .(3) Nilai Ilmiah, yaitu berperan dalam bidang pendidikan dan pengembangan ilmu

Kawasan Situs Purbakala Sangiran memiliki peranan penting bagi sejarah pendidikan manusia purba dan merupakan rangkaian pusat pendidikan yang harus di kembangkan sesuai dengan aturan yang telah ditetapkan oleh RTRW Kabupaten Sragen dan RTRW Kabupaten Karaganyar. Berdasarkan Peraturan Daerah No 11 tahun 2011 tetang Rencana Tata Ruang Wilayah Kabupaten Sragen Tahun 2011-2031,dan Peraturan Daerah No 1 Tahun 2013 Tentang Rencana Tata Ruang Wilayah Kabupaten Karanganyar, kawasan sangiran telah ditetapkan sebagai kawasan cagar budaya (Situs purbakala). Kawasan situs purbakala ini memiliki fungsi khusus yaitu sebagai cagar budaya ilmu pengetahuan dan sejarah budaya. Dengan keberadaan budaya inilah yang akan menjadikan kawasan sangiran memiliki karakter unik dan khas. Sebagai salah satu kawasan terbesar dunia yang memiliki hasil temuan manusia purba, kawasan situs sangiran memiliki daya tarik yang tinggi dalam kegiatan pariwisata. Tidak hanya wisatawan dalam negeri, wisatawan manca negara sangat tertarik untuk melakukan kegiatan pariwisata dan penelitian di kawasan sangiran.

Dengan adanya pembangunan museum Sangiran pada tahun 2011 yang berstandar internasional maka kawasan Sangiran menjadi salah satu kawasan wisata budaya pilihan bagi para wisatawan baik domestik maupun mancanegara. Berdasarkan data statistik wisata kabupaten Sragen pada tahun 2013 terlihat kunjungan wisata dari tahun 2002 hingga 2013 mengalami peningkatan yang cukup signifikan yaitu meningkat sebesar sebesar $163,56 \%$ hal ini terjadi tepat setelah museum dibangun. Hal ini cukup terlihat karena setiap hari para wisatawan terus meningkat dan merupakan dampak yang sangat positif, sehingga kawasan ini telah berhasil menjadikan karakter bagi wilayah dan menjadi ciri khas di Kabupaten Sragen. Dengan meningkatnya pengunjung, maka ilmu pengetahuan manusia purba dapat dinikmati oleh masyarakat luas. Semakin tinggi pengunjung yang datang, maka akan menjadikan peluang usaha bagi masyarakat, maka mulailah masyarakat menyediakan sarana pelayanan pariwisata bagi pengunjung. Kegiatan ini adalah kegiatan yang positif bagi masyarakat karena dapat menjadikan perekonomian meningkat. 
Jurnal Planologi Vol. 15, No. 1, April 2018

Kawasan Situs Purbakala Sangiran merupakan bagian penting dalam sebuah kawasan karena mengandung nilai budaya tinggi. Perkembangan kawasan tersebut secara tidak langsung akan mempengaruhi Bentuk dan Pola ruang.

\section{METODOLOGI}

Metode penelitian yang akan digunakan dalam studi "Bentuk dan Pola Kawasan Situs Purbakala Sangiran di Kabupaten Sragen dan Kabupaten Sragen" adalah metode kuantitatif dengan menggunakan karangka penelitian deskriptif dan simulasi. Menurut Whitney dalam Nazir (2003), metode deskriptif adalah pencarian fakta dengan interpretasi dengan tepat. Adapun tujuan dari penelitian ini adalah untuk membuat deskripsi, gambaran atau lukisan secara sistematis, faktual adan akurat mengenai fakta-fakta, sifat-sifat serta hubungan antarfenomena yang diselidiki sedangkan simulatif adalah menggunakan permodelan komputer untuk memecahkan dan atau menjawab persoalan suatu yang nyata (Darjosanjoto, 2005).

Metode pendekatan deskriptif dalam kegiatan penelitian ini digunakan untuk mengetahui kondisi wilayah studi yang meliputi hal-hal sebagai berikut :

1. Karakteristik Kawasan Situs Purbakala Sangiran

2. Mengetahui faktor-faktor yang mempengaruhi bentuk dan pola perkembangan Kawasan Situs Purbakala Sangiran

3. Mengetahui Bentuk dan Pola kawasan Situs Purbakala Sangiran

Sedangkan dalam maksud dari pendekatan kuantitatif simulatif adalah dalam proses melakukan analisis menggunakan dasar pengetahuan yang diperoleh dari kajian teori kemudian dilakukan beberapa simulasi dengan menggunakan alat analisis depthmap, aplikasi ini merupakan platform resmi space syntax (open source) yang dikembangkan oleh Space Syntax Laboratory di Barlett School-UCL.

Kegiatan simulative menggunakan data jaringan jalan eksisting yang dipada seluruh kawasan penelitian. Adapun langkah kegiatan simulatif ini memiliki 3 tahapan yaitu connectivity, integrity dan intelgibility. Hasil dari analisis ini kemudian di overlay kan dengan kawasan terbangun yamg ada di kawasan penelitian.

Alat analisis space syntax merupakan salah satu alat yang dapat memberikan hasil temuan berupa konfigurasi ruang. Konfigurasi ruang adalah sebuah wadah yang memiliki hubungan dimana objek-objek saling berhubungan satu dengan yang lain sehingga akan membentuk struktur kawasan yang dapat dimanfaatkan manusia dalam menjalankan setiap 
Jurnal Planologi Vol. 15, No. 1, April 2018

aktivitasnya. Salah satu output dari kegiatan analisis ini adalah diketahui nya bentuk atau struktur kawasan yang dihasilkan berdasarkan nilai pada ke tiga tahap analisis yaitu connectivity, integrity da intelgibility. Hasil ini dapat memperkuat dari temuan studi dan memperkuat teori yang digunakan yaitu urban form.

Pengetian Space Syntax menurut Hillier (2007) adalah adanya pengembangan teori baru mengenai ruang sebagai aspek kehidupan sosial. Seiring dengan waktu, beberapa pengembangan teori ini disusun dalam bentuk simbiosa dengan pengembangan teknik baru untuk analisis ruang, utamanya analisis yang berbasis komputer. Sebagai keluaran utama dari kemajuan ini adalah 'konsep konfigurasi’. Di mana konfi gurasi dimengerti sebagai satu hubungan atau keterkaitan yang ditimbulkan oleh adanya kehadiran bersama (co-presence).

Selain itu disampaikan Hillier dalam buku Space in Machine (2007) bahwa penelitian mengenai space syntax mengalami kemajuan yang sangat pesat seperti yang dilakukan oleh Julienne Hanson (1999) dalam penelitiannya tentang "Decoding Homes and Houses", bersama rekannya meneliti tentang bentuk dan fungsi pada bangunan gedung dengan melihat pengaruh desain dan inovasi gedung terhadap lingkungan kerja. Pada penelitian lainnya yang dilakukan mengenai space syntax dilakukan oleh Steadman (Steadman, 2005), dengan melakukan pencacahan pada bentuk gedung dengan cara klarifikasi geometrik, indikator konstruksu dan kendala lingkungan, hasilnya bahwa terdapat pendekatan baru dalam melakukan pencacahan ruang yang harus disebarluaskan. Secara keseluruhan space syntax akan menjadi salah satu paradigma baru dalam penelitian tentang tata ruang yang juga dapat digabungkan dengan banyak pendekatan lainnya. Hal inilah yang dilakukan oleh space syntax, space syntax dapat menerapkan data fisik dan data sosial dalam satu tampilan gambar serta mencoba memahami bagaimana manusia membuat dan memakai konfigurasi spatial dalam interaksi sosial dan budaya dalam lingkungan binaan (Prasasti, 2013).

Teknik analisis konfigurasi dinamakan space syntax (Darjosanjoto, 2005, disarikan dari Hillier dan Hanson, 1984, dan Hillier, 1997). Space syntax adalah program penelitian dalam kerangka berpikir (paradigma) morfologi dari penelitian lingkungan terbangun (built environment). Menurut Hillier dan Hanson tujuan dari penyusunan program space syntax adalah: 'mengembangkan pemahaman teori mengenai bagaimana ruang bekerja dengan strategi memadukan diskripsi berbasis komputer yang mendasarkan pada aturan mengenai pola ruang dengan pengamatan empiris mengenai bagaimana pola ruang digunakan. Selanjutnya keduanya dikaitkan dengan statistik sederhana. Aksesibilitas sebuah ruang menjadi hal penting dalam sebuah kawasan, kemampuan sebuah ruang "berkomunikasi" 
dengan ruang lain dalam sebuah kawasan. Salah satu temuan yang paling fundamental yang diungkapkan dalam space syntax adalah pola gerak dan interaksi dalam bangunan yang dipengaruhui oleh tata letak (Shidi Pramudito, 2013).

Dalam kegiatan pengembangan kawasan heritage diperlukan perlakuan khusus dan harus merujuk aturan yang telah ditetapkan oleh pemerintah. Sesuai dengan piagam burra yang merupakan acuan dalam kegiatan konservasi dan restorasi manumen dan situs. Konservasi merupakan suatu tindakan pelestarian yang diambil untuk memeilihara dan mengawetkan sesuatu benda dengan teknologi modern dengan upaya untuk menghambat proses kerusakan dan pelapukan lebih lanjut, sehingga umur benda dapat panjang. Pada dasarnya kegiatan konservasi tidak hanya berlaku pada benda saja akan tetapi juga berlaku untk lingkungan agar kondisi terkendali dan mendukung langkah yang diambil guna pelestarian benda/bangunan secara tuntas. Dengan demikian secara fisik kondisi benda akan lebih baik dan lebih tahan terhadap lingkungan. Adapun sistematika diagnosa dan studi konservasi adalah sebagi berikut:

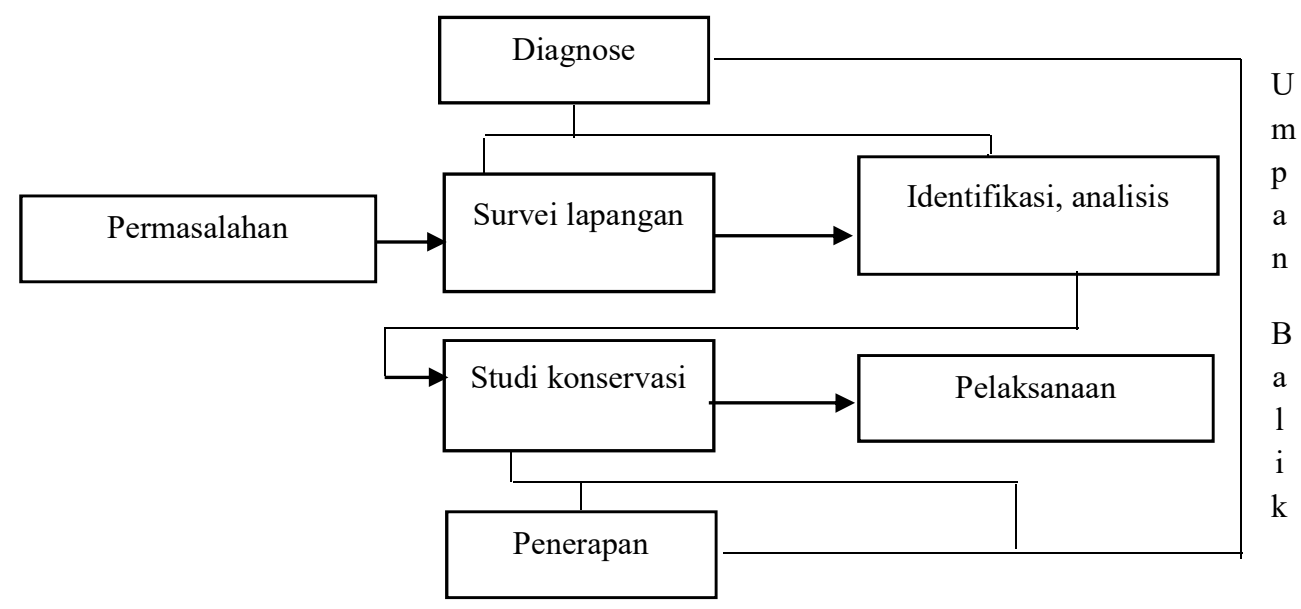

Gambar 1. Sistematika Diagnosa Dan Studi Konservasi Sumber : Pedoman Pengelolaan Peninggalan Sejarah Dan Purbakala, 1991

Telah disebutkan bahwa tempat yang mempunyai signifikan budaya memperkaya kehidupan manusia sering membeikan ikatan rasa yang dalam dan inspiratioanal kepada masyarakat. Tempat yang mempunyai signifikan budaya harus dilestarikan untuk generasi yang akan datang. 
Jurnal Planologi Vol. 15, No. 1, April 2018

Available: http://jurnal.unissula.ac.id/index.php/psa

\section{HASIL DAN PEMBAHASAN}

Sebagai salah satu kawasan yang memiliki potensi tinggi dalam bidang ilmu pengetahuan dan telah di akui oleh UNESSO, situs purbakala sangiran telah memenuhi kriteria bahwa sebuah kawasan cagar budaya dengan ciri dan karakter khusus yang memiliki nilai budaya/sejarah sehingga perlu di lestarikan dan dijaga agar dapat memberikan dapat positif bagi setiap masyarakat. Adapun potensi yang dapat ditemui di kawasan ini adalah ditemukanya fosil dan artefak dari manusia purba dan dilokasi ini telah banyak dilakukan penetilian bahwa pada jaman prasejarah di kawasan ini hidup manusia sejenis homo erectus.

Perkembangan situs purbakala Sangiran, dipengaruhi oleh pola jaringan jalan. Jaringan jalan sendiri memiliki 2 parameter utama dalam kegiatan perkembangan kawasan yaitu ketersediaan jalan dan jaringan transportasi. Ketersediaan jalan lokal dan lingkungan merupakan factor utama dalam kegiatan pembangunan mulai dari permukiman, perdagangan, jada dan pembangunan museum baru selalu mengikuti arah perkembangan pola jalan yang telah ada. sebagai pembentuk struktur kawasan atau kerangka kawasan, ketersediaan jalan merupakan faktor yang sering dijumpai dalam setiap perkembangan kawasan, dimana embrio utama adalah jalan sehingga di lokasi tersebut akan muncul kegiatan baru. Jaringan jalan merupakan jalur penghubung transportasi yang ada di kawasan situs purbakala sangiran, jaringan jalan ini telah dapat melayani seluruh masyarakat di dalam dan diluar kawasan situs purbakala sangiran secara pribadi karena di dalam kawasan belum terdapat transportasi masal.

Pola jaringan jalan yang ada di Kawasan Situs Purbakala Sangiran membentuk pola radial network dimana seluruh jaringan jalan berpencar sesuai dengan topografi yang ada di kawasan. Pola jaringan ini berbentuk seperti percabangan dan membentuk akses kecil untuk kawasan yang lebih kecil yaitu akses menuju ke kawasan permukiman. Sehingga dapat diketahui bahwa segala bentuk perkembangan kawasan yaitu munculnya bangunan baru di situs purbakala sangiran dapat ditemukan bahwa munculnya bangunan selalu pada lokasi yang sudah terdapat jaringan jalan. pola perkembangan kota yang berbentuk seperti pita, yang merupakan akibat dari peningkatan jaringan jalan, pengembangan jalur yang umumnya terjadi di luar rencana tata ruang. Pengembangan jalur yang berada di kiri dan kanan jalan yang ramai menjadikan faktor minat penduduk untuk melakukan kegiatan berupa penyediaan barang dan jasa. Pola ini menunjukan tidak meratanya area perkotaan di semua bagian sisi luar daripada kota utama. Pertumbuhan paling pesat terjadi di sepanjang jalur transportasi, terutama di area jalan yang menjari dari pusat kota (Yunus, 2000). 
Menurut Larry S.Bourne: Internal Structure Of City,1982 mendefinisan Urban form atau bentuk kota adalah pola ruang atau tatanan dari setiap unsur yang berada dalam area perkotaan,baik bangunan maupun guna lahan ( secara kolektif membentuk lingkungan terbangun) termasuk juga tatanan kelompok-kelompok sosial kegiatan ekonomi dan institusi publik. Dari proses analisis kondisi dan pola ruang terbuka dan kinerja ruang melalui simulasi yang telah dilakukan, maka muncul temuan secara umum Kawasan Situs Purbakala Sangiran baik yang berada di Kabupaten Sragen dan Kabupaten Karanganyar agar dapat mengarah pada kondisi yang optimal, yaitu: Nilai integrasi lokal, maupun integrasi visual menggambarkan kondisi ruang yang ada sehingga dapat dilihat ruang mana yang potensial untuk dikembangkan agar ruang dapat saling mendukung satu sama lain; Kecenderungan dan kemungkinan pola pergerakan yang terjadi akan sangat berpengaruh pada kondisi lapangan, sehingga diperlukan penyesuaian agar peran ruang dapat lebih optimal.

\section{Pola Kawasan Situs Purbakala Sangiran}

Untuk mengetahui bentuk dan pola kawasan situs purbakala di situs purbakala sangiran, penulis menggunakan alat analisis spasial yaitu analisis space syntax. Analisis ini memiliki 3 tahapan yaitu: Connectivity; Integrity dan Intelgibility. Berikut adalah hasil analisis bentuk dan pola kawasan situs purbakala Sangiran.

Tabel 1. Analisis Pola Situs Purbakala Sangiran

\begin{tabular}{|c|c|c|c|}
\hline $\begin{array}{c}\text { Nama } \\
\text { Museum }\end{array}$ & Lokasi & Konektivitas & Nilai Integrity \\
\hline $\begin{array}{l}\text { Museum } \\
\text { Krikilan }\end{array}$ & 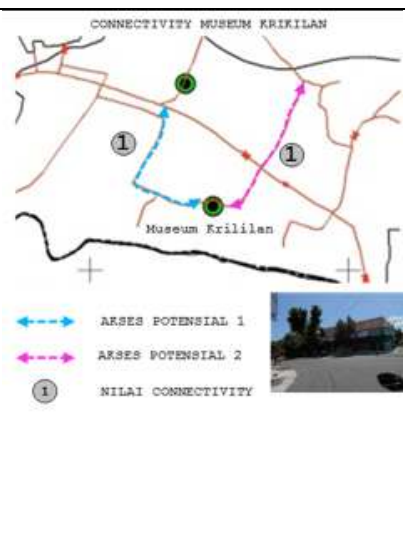 & $\begin{array}{l}\text { terdapat } 2 \text { jaringan jalan yang } \\
\text { potensial untuk menjangkau } \\
\text { lokasi museum krikilan. Akses } \\
1 \text { merupakan jaringan jalan } \\
\text { yang kurang diminati oleh para } \\
\text { pengunjung karena jaringan ini } \\
\text { memasuki perkampungan } \\
\text { dengan lebar jalan yang } \\
\text { sempit. Untuk akses } 2 \text { adalah } \\
\text { jaringan jalan pilihan utama } \\
\text { bagi para pengunjung wisata } \\
\text { karena cukup mudah dan dekat } \\
\text { jalan utama. }\end{array}$ & 0.30555648 (kuat) \\
\hline
\end{tabular}


Jurnal Planologi Vol. 15, No. 1, April 2018

\begin{tabular}{|c|c|c|c|}
\hline $\begin{array}{l}\text { Museum } \\
\text { Ngebung }\end{array}$ & 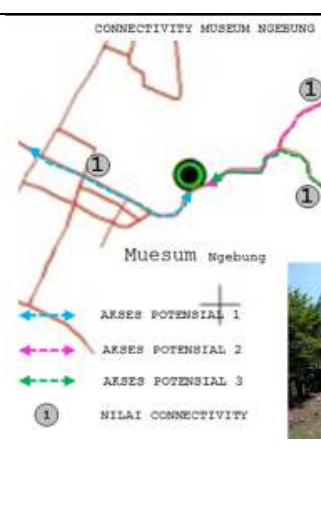 & $\begin{array}{l}\text { terdapat } 3 \text { jaringan jalan yang } \\
\text { potensial untuk menjangkau } \\
\text { lokasi museum Ngebung } \\
\text { Museum Ngebung berada di } \\
\text { antara ketiga jalan ttersebut dan } \\
\text { merupakan bangunan baru. } \\
\text { Akses untuk menuju lokasi ini } \\
\text { cukup baik dengan lebar } 4-5 \\
\text { meter. Jaringan jalan ini cukup } \\
\text { aktif karena setiap harinya } \\
\text { dimafaatkan sebagai sarana } \\
\text { bagi masyarakat desa }\end{array}$ & 0.28318626 (lemah) \\
\hline $\begin{array}{l}\text { Museum } \\
\text { Bukuran }\end{array}$ & $\stackrel{4}{\longrightarrow \rightarrow}$ & $\begin{array}{l}\text { terdapat } 2 \text { jaringan jalan yang } \\
\text { potensial untuk menjangkau } \\
\text { lokasi museum Bukuran } \\
\text { Keberadaan Museum Bukuran } \\
\text { berada diantara kedua jalan } \\
\text { dan juga merupakan bangunan } \\
\text { baru. Akses jalan (1) menuju } \\
\text { museum ini cukup strategis, } \\
\text { karena jalan ini searah dengan } \\
\text { jalan menuju Museum } \\
\text { Krikilan. }\end{array}$ & 0.30423653 (lemah) \\
\hline $\begin{array}{l}\text { Museum } \\
\text { Manyarej } \\
\text { o }\end{array}$ & 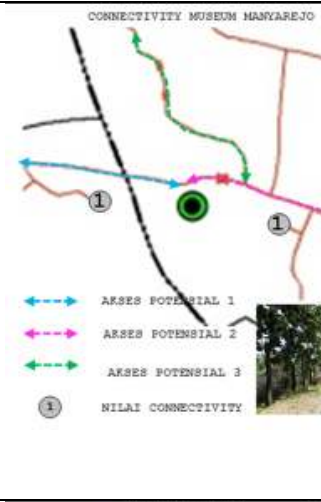 & $\begin{array}{l}\text { Ketiga jalan ini merupakan } \\
\text { jalan lingkungan dengan lebar } \\
4-5 \text { meter. Fungsi jalan } \\
\text { potensial } 1,2 \text { dan } 3 \text { ini adalah } \\
\text { sebagai penghubung antar } \\
\text { desa sehingga jalan ini } \\
\text { tergolong jalan lingkungan. } \\
\text { Letak Museum Manyarejo } \\
\text { terjepit, belum ada jaringan } \\
\text { jalan yang dapat } \\
\text { menghubungkan langsung } \\
\text { dengan jalan utama kota. }\end{array}$ & 0.3176477 (kuat) \\
\hline $\begin{array}{l}\text { Museum } \\
\text { Dayu }\end{array}$ & 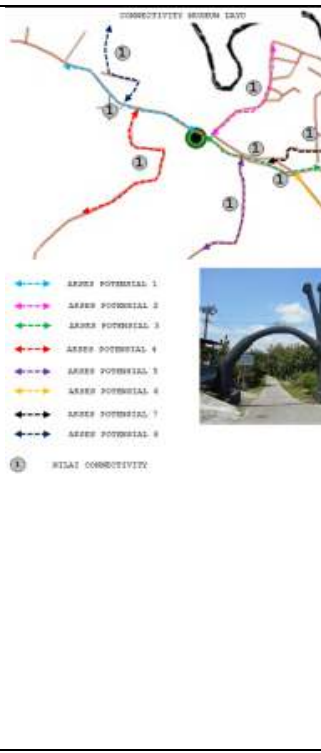 & $\begin{array}{l}\text { terdapat } 2 \text { jaringan jalan yang } \\
\text { memiliki potensi tinggi menuju } \\
\text { lokasi museumi. jalan } \\
\text { potensial } 1 \text { merupakan jalan } \\
\text { paling strategis dikarenakan } \\
\text { jalan ini terusan Jl. Solo- } \\
\text { Purwodadi. jalan potensial } 2 \\
\text { menuju jalan Kabupaten } \\
\text { Sragen-Kabupaten } \\
\text { Karanganyar-Kota } \\
\text { (Mojosongo). Untuk jalan } \\
\text { potensial 3-8 adalah jalan } \\
\text { lingkungan yang dimanfaatkan } \\
\text { masyarakat untuk kegiatan } \\
\text { sehari-hari. Jalan (1) adalah } \\
\text { akses termudah yang dapat } \\
\text { para pengunjung yang berasal } \\
\text { dari Kabupaten Karanganyar, }\end{array}$ & 0.49159461 (kuat) \\
\hline
\end{tabular}


Jurnal Planologi Vol. 15, No. 1, April 2018

Available : http://jurnal.unissula.ac.id/index.php/psa

\begin{tabular}{|c|c|}
\hline & $\begin{array}{l}\text { Kabupaten Sragen dan Kota } \\
\text { Solo. }\end{array}$ \\
\hline Nilai Intelgibility & Keterangan \\
\hline Randah & $\begin{array}{l}\text { Dari peta garis tersebut, dapat dilihat bahwa terdapat } \\
\text { hubungan yang saling terkait. Pada beberapa garis/ruang } \\
\text { luar, cukup terlihat jelas ada yang memiliki nilai } \\
\text { integrasi yang hampir sama }(0,317,0,306 \text { dan } 0,304) \text {. } \\
\text { Namun di sisi lain ditemukan bahwa garis yang kurang } \\
\text { terintegrasi secara global tetapi terintegrasi secara lokal. } \\
\text { Hal ini menunjukkan bahwa secara lokal garis ini } \\
\text { memiliki banyak pilihan untuk akses, namun secara } \\
\text { global letaknya kurang terintegrasi. Dengan nilai } \\
\text { integritas yang tinggi maka akan dapat menjadi } \\
\text { penghubung antara beberapa museum tersebut. }\end{array}$ \\
\hline Nilai Intelgibility & $\begin{array}{l}\text { Nilai intelgibility yang terjadi di kawasan situs Sangiran } \\
\text { adalah rendah }(0,0127) \text {. Hal ini menyiratkan bahwa } \\
\text { korelasi antara konektivitas dan integritas di kawasan } \\
\text { tersebut rendah. Hal ini menjadikan ruang yang ada di } \\
\text { Kawasan Situs purbakala Sangiran tidak memiliki pusat } \\
\text { kegiatan utama, sehingga kecenderungan ruang akan } \\
\text { terpencar. }\end{array}$ \\
\hline
\end{tabular}

Tabel 2. Bentuk Kawasan Situs Purbakala Sangiran

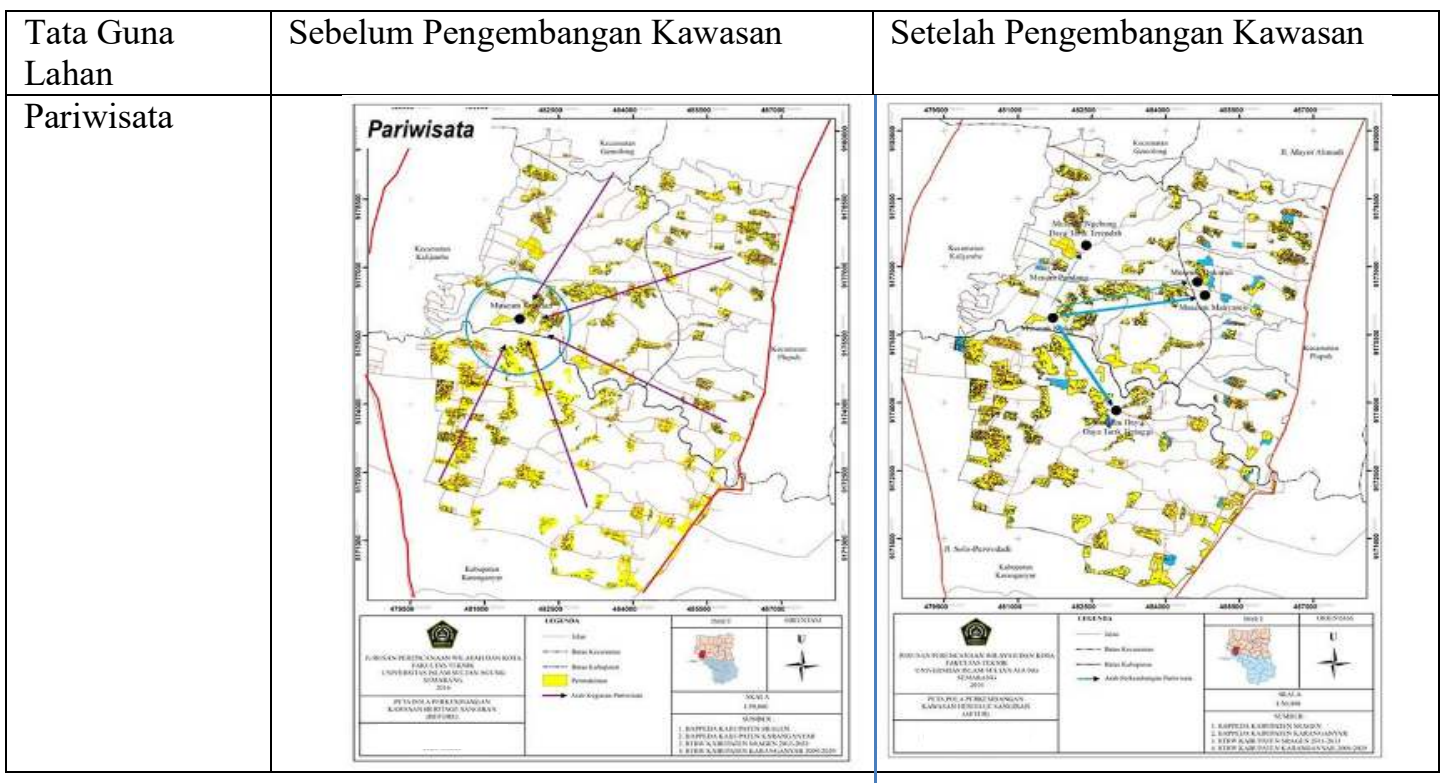

Mila Karmilah, Nyandra Sari Magfiroh I 90 Using Space Syntax To Determine The Form ... 


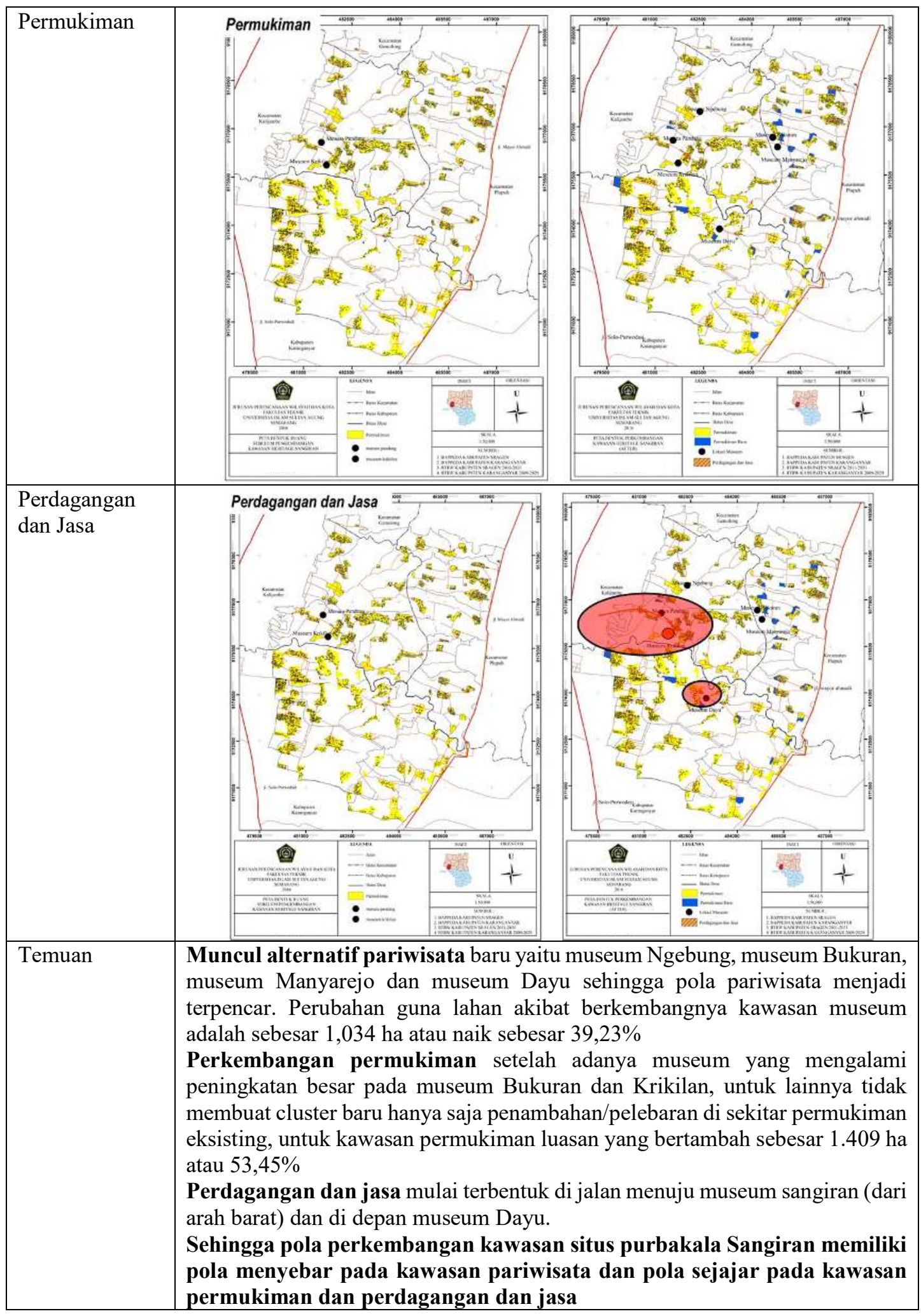

Mila Karmilah, Nyandra Sari Magfiroh I 91 Using Space Syntax To Determine The Form ... 
Jurnal Planologi Vol. 15, No. 1, April 2018 Available : http://jurnal.unissula.ac.id/index.php/psa

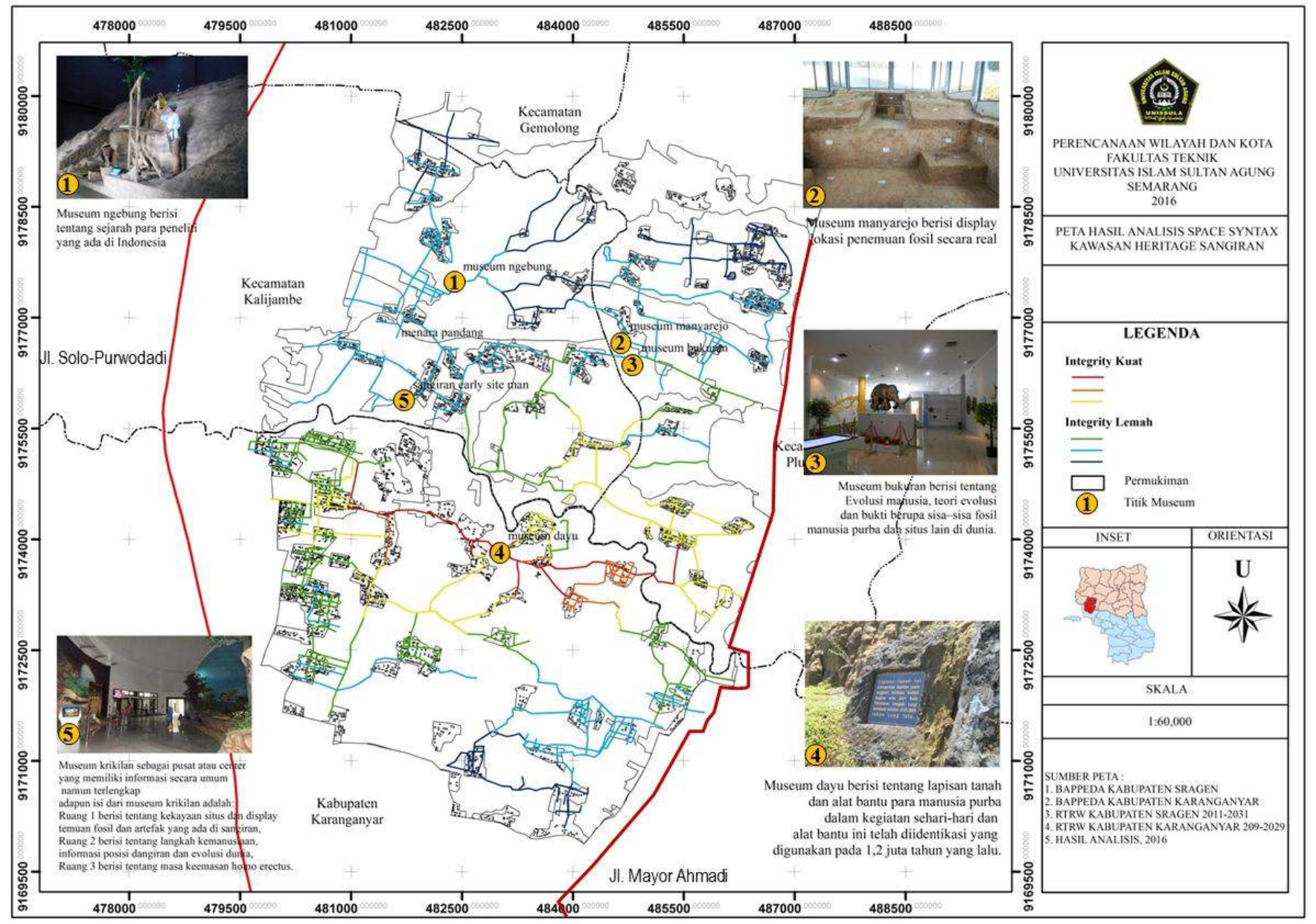

Gambar 2. Temuan Studi

Sumber : Analisis Penulis, 2016

Mila Karmilah, Nyandra Sari Magfiroh I 92 Using Space Syntax To Determine The Form ... 


\section{KESIMPULAN DAN SARAN}

\section{Kesimpulan}

Berdasarkan analisis yang telah dilakukan dalam bab sebelumnya, kesimpulan yang bisa di ambil adalah sebagai berikut:

1. Bentuk Kawasan Situs Purbakala Sangiran

Hasil analisis space syntax yaitu R2 $(\mathrm{R}$ Square) $=0,012714$. Nilai ini menunjukan bahwa nilai intelgibilty kawasan rendah sehingga kecenderungan kawasan adalah terpecah, sehingga dapat diketahui Bentuk Kawasan Situs Purbakala Sangiran dapat terlihat seperti Fragment cities (terpencar), karena lokasi cluster-cluster museum cenderung terpencar dan tidak memiliki pusat kegiatan kurang terarah. Bentuk kawasan Situs Purbakala Sangiran berdasarkan teori bentuk ruang yang dikemukakan oleh yunus, 2000 berada pada katagori bentuk tidak kompak yaitu Fragment cities (terpencar) yang bermakna setiap perluasan atau perkembangan kawasan tidak langsung menyatu dengan induk atau pusat.

2. Pola Kawasan Situs Purbakala Sangiran

Dari analisis space syntak menghasilkan nilai intelgibility yaitu R2 (R Square) = 0,012714 sehingga untuk pola perkembangan pariwisata di situs purbakala sangiran yaitu pola menyebar atau dispersed pattern sesuai dengan teori yang dikemukakan oleh Alexsander J.W : 1999 kawasan ini memiliki kegiatan ekonomi yang homogeny. Akan tetapi untuk pola perkembangan permukian dan perdagangan dan jasa yaitu sejajar dengan jaringan jalan.

3. Terdapat beberapa hal yang dapat mempengeruhi perubahan bentuk dan pola kawasan situs perbakala sangiran yaitu pola jaringan jalan, sumber daya alam, daya dukung lahan dan kebijakan pemerintah.

\section{Saran}

Saran diberikan dengan tujuan agar meningkatkan kegiatan pengembangan Kawasan

Situs Purbakala Sangiran berikut ini merupakan beberapa saran bagi pemerintah dan masyarakat:

Adapun saran bagi pemerintah adalah sebagai berikut:

1. Pembatasan jumlah wisatawan untuk menjaga kualitas kawasan Situs Purbakala Sangiran karena ditakutkan akan terjadi degadrasi lingkungan.

2. Pembuatan paket wisata untuk memberikan pelayanan wisata yang berkualitas dalam bidang wisata edukasi 
Jurnal Planologi Vol. 15, No. 1, April 2018

Available: http://jurnal.unissula.ac.id/index.php/psa

3. Kegiatan pengembangan kawasan Situs Purbakala Sangiran sebaiknya disertai dengan pembangunan infrastruktur jalan yang memadai sehingga para wisatawan mudah untuk menjangkau.

4. Pengendalian kawasan terbangun untuk jangka waktu panjang, kerana akan muncul bangunan-bangunan baru terutama perdagangan dan jasa

5. Sosialisasi kepada masyarakat terkait pelestarian kawasan situs

6. Masyarakat harus senantiasa menjaga dan memelihara kawasan Situs Purbakala Sangiran

7. Masyarakat diharapkan dapat ikut serta dalam setiap pengembangan kawasan terutama dalam bukan hanya dalam hal kegiatan penyediaan perdagangan dan jasa untuk para wisatawan namun pada usaha melestarikan budaya dan cagar budaya di sekitar kawasan

8. Masyarakat di harapkan taat dan patuh terhadap peraturan tata ruang yang terkait dengan pembangunan baru di sekitar kawasan museum

\section{DAFTAR PUSTAKA}

Anonim. (2010). Undang-Undang Nomor 11 Tahun 2010 Tentang Cagar Budaya Anonim. (2007). Undang -Undang No 26 Tahun 2007 Tentang Rencana Tata Ruang.

Anonim. (2011). Peraturan Daerah No 11 tahun 2011 tetang Rencana Tata Ruang Wilayah Kabupaten Sragen Tahun 2011-2031

Anonim. (2013) Peraturan Daerah No 1 Tahun 2013 Tentang Rencana Tata Ruang Wilayah Kabupaten Karanganyar

Bourne, Larry S. (1982). Internal Structure of the City, Readings on Urban form, Growth and Polic. New York: Oxford University Press.

Budiharjo, Eko (Ed.), (1997), Arsitektur Pembangunan dan Konservasi, Penerbit Djambatan, Jakarta

Darjosanjoto, E. (2005). "Kembang Jepun” : Jalan Dominan Kota Surabaya, dalam Dimensi Teknik Arsitektur, Vol. 33, Nomor 2, 143 - 152.

Hillier. B (2007). "Space in The Machine: A Configurational Theory of Architecture" Press Syndicate of The University of Cambridge London

Yunus, Hadi Sabari. (2000). Struktur Tata Ruang Kota, Yogyakarta: Penerbit Pustaka Pelajar. Krisnawati, Lilik dan Rima, Suprihardjo Dewi. (2014). Arahan Pengembangan Kawasan Cagar Budaya Singosari Malang sebagai Heritage Tourism, dalam Jurnal Teknik Pomits, Vol 3, Nomor 2, hal 154-159 
Jurnal Planologi Vol. 15, No. 1, April 2018

Available : http://jurnal.unissula.ac.id/index.php/psa

Shidi Pramudito. (2013). Analisis Pola Tata Ruang Terbuka Tepian Sungai Winongo Di Kampung Budaya Bangunrejo, dalam Jurnal Arsitektur KOMPOSISI, Vol 10, Nomor 4 239-254.

Prasasti. W dan Mutiari. D (2013). Analisis Space Syntax Rumah Susun Berbasis Gang Kampung, dalam Simposium Nasional RAPI XII, FT UMS 